\title{
The Ability of Lysate-PRF Induces Proliferation of Fibroblast Cells in Endodontic Regenerative Therapy
}

\author{
Ratna Meidyawati, Endang Suprastiwi \\ Department of Conservative Dentistry, Faculty of Dentistry, Universitas Indonesia, Jakarta, Indonesia \\ Email: esuprastiwi@yahoo.co.id
}

How to cite this paper: Meidyawati, R. and Suprastiwi, E. (2018) The Ability of Lysate-PRF Induces Proliferation of Fibroblast Cells in Endodontic Regenerative Therapy. Open Journal of Stomatology, 8, 182-187. https://doi.org/10.4236/ojst.2018.85017

Received: April 2, 2018

Accepted: May 20, 2018

Published: May 23, 2018

Copyright (c) 2018 by authors and Scientific Research Publishing Inc. This work is licensed under the Creative Commons Attribution International License (CC BY 4.0).

http://creativecommons.org/licenses/by/4.0/

\section{(c) (i) Open Access}

\begin{abstract}
Lysate-platelet rich fibrin (Lysate-PRF) is a scaffold that contains growth factor. Aim: To analyze the ability of two types of Lysate-PRF in inducing the proliferation of fibroblast cells. Material \& Methods: Microplate with 24 wells each filled $200 \mu \mathrm{l}$ suspension DMEM $+10 \%$ FBS and $10 \times 104$ fibroblasts. Then FBS is replaced with a concentration of $1 \%$, for serum starvation process. Each 3 wells were exposed with 50\%, 25\%, 12.5\% Lysate-PRF and $50 \%, 25 \%, 12.5 \%$ Lysate A-PRF respectively. Three other wells are exposed to $10 \%$ FBS. Microplate was incubated for 24 hour at $37^{\circ} \mathrm{C}$ with $5 \% \mathrm{CO}_{2}$. The growth of fibroblast was calculated by automatic cell counter. Results: The highest mean value of the Lysate-PRF group was at 12.5\% (312.833) while the Lysate A-PRF group at 25\% (303.500). If all the groups compared did not show any significant differences. Conclusions: Lysate-PRF and Lysate A-PRF have the same ability as 10\% FBS in inducing fibroblast cell proliferation or the same as physiological condition.
\end{abstract}

\section{Keywords}

Lysate-PRF, Proliferasi, Fibroblast, Regenerative, Endodontic

\section{Introduction}

Fibroblasts of the pulp are mostly present in the cell-rich zone and can differentiate according to the received signal. The odontoblast cell is one of the results of fibroblast cell differentiation; because of this ability, the use of fibroblast in the study may present a biological response [1] [2]. Regeneration is a dynamic process including inflammatory phases, granulation, re-epithelialization and tissue remodeling. Each phase involves cytokines, endogenous growth factors 
and proteases, so that pulmonary regeneration also requires cytokine sources and growth factor [3].

Platelet rich fibrin (PRF) is a blood-processed product with one centrifugation step and no additional anticoagulants and bovine serum [4]. Lysate-PRF is part of a PRF containing cytokines, structured glycoproteins, and glican chains that are natural initiators in angiogenesis. Growth factors present in PRF are platelet derived growth factor (PDGF), transforming growth factor $\beta 1$ (TGF $\beta 1$ ) and insulin like growth factor (IGF). PRF can serve as a biological mediator that controls the proliferation, differentiation, and synthesis of extracellular matrix. The use of PRF as a scaffold and media containing growth factor is ideal for endodontic regenerative care [5] [6]. The form of the PRF gel may act as a viable barrier that limits the healing area to the outside environment that does not support the healing process [7]. In 2010, Huang et al. examined the effect of PRF on human pulp cells. The results showed that the growth factor of PRF can induce the proliferation and differentiation of pulp cells associated with secondary dentin formation [8].

Advances in Lysate-PRF manufacturing technology provide opportunities for endodontic regenerative care. This study will test and compare Lysate-PRF and Lysate A-PRF capabilities in fibroblast cell proliferation using a PBS 10\% control group that can describe physiological processes. The results of this study can be developed and utilized for endodontic regeneration treatments.

\section{Materials \& Methods}

\subsection{Preparation of Lysate PRF}

Human blood is taken intravenously from a healthy 32 year old man, inserted into 2 tubes each of $20 \mathrm{ml}$. In lysate-PRF the blood was centrifuged for $14 \mathrm{mi}-$ nutes with a spin speed of $1500 \mathrm{rpm}$ and lysate A-PRF for 12 minutes at a speed of $2700 \mathrm{rpm}$ on normal temperature. The results of centrifuge form three layers of platelet poor plasma (PPP) at the top layer, PRF in the middle, and red blood cells at the bottom (Figure 1). The PRF layer was taken and then incubated for 24 hours at $4^{\circ} \mathrm{C}$. After incubation, the remaining fibrin will settle at the bottom of the tube and its supernatant is called lysate-PRF. Lysae-PRF is inserted into a $2 \mathrm{ml}$ eppendorf tube and stored at $-20^{\circ} \mathrm{C}$. Before use each diluted to concentrations of $50 \%, 25 \%$ and $12.5 \%$.

\subsection{Fibroblast}

The fibroblast cells are obtained from cultured crystalline fibroblast cells. $200 \mu \mathrm{l}$ of $10 \times 104$ fibroblast $/ \mathrm{ml}$ suspension in DMEM $+10 \%$ FBS were placed into each well at 24 microplate wells (Iwaki $^{\mathrm{im}}$ ), in incubation for 24 hours at $37^{\circ} \mathrm{C}$ with $5 \%$ $\mathrm{CO}_{2}$. The media on the well was aspirated and rinsed with PBS then replaced with a DMEM medium containing $1 \%$ FBS for serum starvation [10].

Of 24 wells used only 21 wells and each test group each uses 3 wells i.e. group 1; 50\% lysate-PRF, group 2; $25 \%$ lysate-PRF, group 3; $12.5 \%$ lysate-PRF, group 4; 

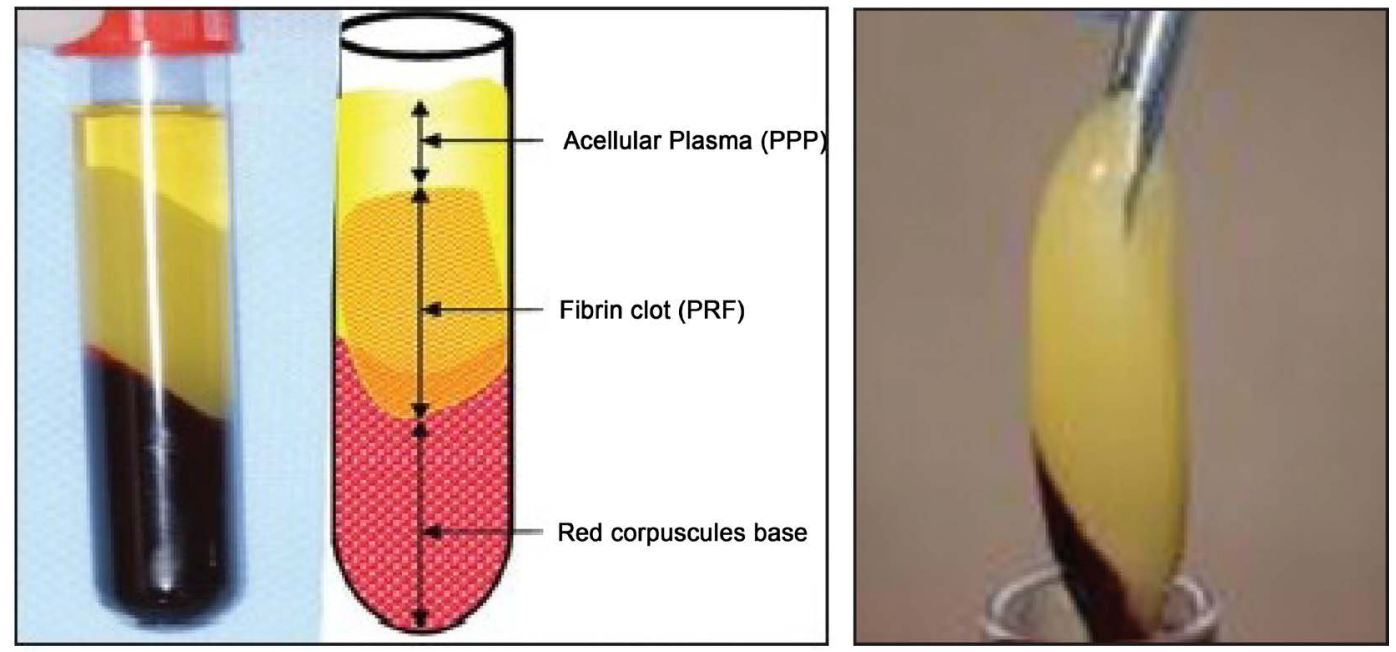

Figure 1. Left: Blood on the vacutainer tubes after centrifugation, divided into 3 layers (lower layers of red blood cells, middle layer of fibrin clumps, upper layer of the aselular plasma); Right: PRF [9].

$50 \%$ lysate A-PRF, group 5; $25 \%$ lysate A-PRF, group $6 ; 12.5 \%$ lysate A-PRF and 3 other wells for control group with $10 \%$ PBS, then incubated for 48 hours at $37^{\circ} \mathrm{C}$ with $5 \% \mathrm{CO}_{2}$. The growth of fibroblasts was calculated by duplo in each group by using automatic cell counter (Luna-II ${ }^{\mathrm{mw}}$, Logos Biosystems).

\subsection{Data Analysis}

Data were analyzed using SPSS 22 with One Way ANOVA statistic test.

\section{Results}

In Table 1, the highest mean values in the Lysate-PRF group were at a concentration of $12.5 \%$ while in the Lysate A-PRF group at $25 \%$ concentration. Average values in all groups showed no significant difference.

In Table 2, if the between group is compared with either control or with the treatment group, the result is no significant difference. This indicates that both Lysate-PRF and Lysate A-PRF capabilities are similar to the control group or $10 \%$ PBS.

\section{Discussion}

In this study used fibroblasts as objects because fibroblast is a major component of pulp tissue constituents that have the activity of proliferation and differentiation are easily observed [11].

In addition, the use of fibroblasts from standardized ready-to-use preparations may represent general tissue conditions because they share biological properties.

To attenuate fibroblast, a serum starvation method is used, which is a standard microbiological procedure for synchronizing phases in cells. Serum starvation is performed for 48 hours for fibroblast cells to undergo cell arrest conditions and cannot replicate DNA for cleavage. Conditions in prolonged G0/G1 
Table 1. Mean and standard deviation of total cells $(\mathrm{cell} / \mathrm{mL})$ in the control group, Lysate-PRF and Lysate A-PRF.

\begin{tabular}{ccccc}
\hline Group & $\mathrm{n}$ & mean (SD) & $95 \mathrm{CI}$ & $\mathrm{p}$ \\
\hline 10\% PBS & 3 & $260.500(18.187)$ & $215.322-305.678$ & 0.315 \\
50\% Lysate-PRF & 3 & $259.333(25.477)$ & $196.045-322.621$ & \\
25\% Lysate-PRF & 3 & $305.667(19.902)$ & $355.106-256.228$ & \\
12.5\% Lysate-PRF & 3 & $312.833(25.320)$ & $375.731-249.936$ & \\
50\% Lysate A-PRF & 3 & $285.333(40.646)$ & $386.303-184.363$ & \\
25\% Lysate A-PRF & 3 & $303.500(57.765)$ & $446.995-160.005$ & \\
$12.5 \%$ Lysate A-PRF & 3 & $261.167(44.501)$ & $371.713-150.620$ & \\
\hline
\end{tabular}

*test of meaning with Anova one way, $\mathrm{p}<0.05$.

Table 2. P-value between control group and Lysate-PRF (50\%, 25\%, 12.5\%) with Lysate A-PRF roup (50\%, 25\%, 12.5\%).

\begin{tabular}{ccccc}
\hline & $10 \%$ PBS & $\begin{array}{c}50 \% \text { Lysate } \\
\text { A-PRF }\end{array}$ & $\begin{array}{c}25 \% \text { Lysate } \\
\text { A-PRF }\end{array}$ & $\begin{array}{c}12.5 \% \text { Lysate } \\
\text { A-PRF }\end{array}$ \\
\hline 10\% PBS & & 1.00 & $1, .00$ & 1.00 \\
$50 \%$ Lysate-PRF & 1.00 & 1.00 & 1.00 & 1.00 \\
25\% Lysate-PRF & 1.00 & 1.00 & 1.00 & 1.00 \\
$12.5 \%$ Lysate-PRF & 1.00 & 1.00 & 1.00 & 1.00 \\
\hline
\end{tabular}

${ }^{\star}$ Post Hoc Tamhane significance test with $\mathrm{p}<0.05$.

cell phases in cell arrest may cause apoptosis. According to Liu et al. (2004) the occurrence of DNA fragmentation as an early sign of cell apoptosis performed serum starvation for 48 hours [12].

To produce 2 types of lysate-PRF centrifugation with different times and speeds taken from the same donor, so that the results are not biased. This has an impact on the composition and concentration of growth factors such as TGF-B, PDGF, VEGF and bFGF [13].

Ghanaati et al. (2014) states that the difference in speed and time of centrifugation will produce different PRFs. In A-PRF sizes, the shape and density of the particles is smaller with the distribution of platelets and neutrophil granulocytes more evenly compared with PRF [14].

Incubation on PRF for 24 hours with a temperature of $-20^{\circ} \mathrm{C}$ aims to obtain platelet lysate. According to Anitua et al. (2010) the lysate form has a higher growth factor concentration than PRF. Growth factors of PDGF and TGF- $\beta$ in regeneration play a role in forming collagen which plays a role for soft tissue healing and callus formation in healing of hard or bone tissue [15]. PDGF synchronizes migration and proliferation of mesenchymal cells, whereas TGF- $\beta$ stimulates matrix synthesis such as fibronectin and collagen type I According to Vahabi et al. (2015) the supernatant (lysate) of the PRF has the ability to increase the proliferation of human gingival fibroblasts [16]. 
In Table 1 and Table 2, average values in all groups were similar and compared between $10 \%$ PBS, 50\%, 25\% and $12.5 \%$ lysate PRF and lysate A-PRF groups did not differ significantly. These results indicate that both the PBS 10\% group, the lysate PRF group and the A-PRF lysate group have the same ability against the proliferation of fibroblast cells. PBS $10 \%$ is a physiological fluid that can present physiological conditions. So the conclusions lysate PRF and lysate A-PRF have the same ability with $10 \%$ PBS or physiological conditions. This result is consistent with research conducted by Huang et al. (2010) on pulp cells, that PRF is a mitogen that can increase pulp cell proliferation. 8 Whereas in previous studies, it was stated that PRF can trigger the proliferation of fibroblast cells in gingival tissue, ligament periodontium, and osteoblast cells [17].

The concentration of lysate PRF and lysate A-PRF has no effect on the effect of fibroblast cell proliferation, this is in accordance with previous studies which proved that cell proliferation rates are not correlated with increased concentration. According to Vahabi (2015) the ideal optimal concentration for cell proliferation is 2.5 times the platelet count in the blood, which normally ranges from 150,000 to 400,000 per microliter [16]. The proliferation rate is related to $\mathrm{pH}$ and platelet concentration. In growth media has a standard $\mathrm{pH}$ ranging from 7.2 7.8, $\mathrm{pH}$ for optimal cell growth [18].

In this study, the proliferation of fibroblast cells in 50\% lysate A-PRF did not give optimal results because of high platelet concentration, a decrease in $\mathrm{pH}$ of the media was marked by the change of color toward clear white opaque to yellowish color different from $25 \%$ concentration and $12.5 \%$. The value of fibroblasts at $25 \%$ lysate PRF concentration is not higher than $12.5 \%$ although this is not influenced by $\mathrm{pH}$, but this is probably due to an adequate number of growth factors for reduced regeneration. This is thought to lead to not seemingly statistically significant differences.

\section{Conclusion}

The ability of Lysate-PRF and Lysate A-PRF in inducing fibroblat cell proliferation is equal to $10 \%$ FBS or has the same ability as physiological conditions.

\section{References}

[1] Pashley, D.H., Walton, R.E. and Slavkin, H.C. (2002) Histology and Physiology of the Dental Pulp. In: Ingle, J.I. and Bakland, L.K., Eds., Endodontics, 5th Edition, BC Decker Inc., Hamilton, 25-55.

[2] Hargreaves Kenneth, M.C.S. (2011) Cohen's Pathways of the Pulp. 10th Edition. Vol. 210, Elsevier, Amsterdam, 424-425.

[3] Traversa, B. and Sussman, G. (2001) The Role of Growth Factors, Cytokines and Proteases in Wound Management. Primary Intention, 9, 161-167.

[4] Choukroun, J., et al. (2006) Platelet-Rich Fibrin (PRF): A Second-Generation Platelet Concentrate. Part V: Histologic Evaluations of PRF Effects on Bone Allograft Maturation in Sinus Lift. Oral Surgery, Oral Medicine, Oral Pathology, Oral Radiology, and Endodontology, 101, 299-303. 
https://doi.org/10.1016/j.tripleo.2005.07.012

[5] Sunitha Raja, V. and Munirathnam Naidu, E. (2008) Platelet-Rich Fibrin: Evolution of a Second-Generation Platelet Concentrate. Indian Journal of Dental Research, 19, 42-46. https://doi.org/10.4103/0970-9290.38931

[6] Dohan Ehrenfest, D.M., Del Corso, M., Diss, A., Mouhyi, J. and Charrier, J.-B. (2010) Three-Dimensional Architecture and Cell Composition of a Choukroun's Platelet-Rich Fibrin Clot and Membrane. Journal of Periodontology, 81, 546-555. https://doi.org/10.1902/jop.2009.090531

[7] Hiremath, H., Motiwala, T., Jain, P. and Kulkarni, S. (2014) Use of Second-Generation Platelet Concentrate (Platelet-Rich Fibrin) and Hydroxyapatite in the Management of Large Periapical Inflammatory Lesion: A Computed Tomography Scan Analysis. Indian Journal of Dental Research, 25, 517-520. https://doi.org/10.4103/0970-9290.142556

[8] Huang, F.-M., Yang, S.-F., Zhao, J.-H. and Chang, Y.-C. (2010) Platelet-Rich Fibrin Increases Proliferation and Differentiation of Human Dental Pulp Cells. Journal of Endodontics, 36, 1628-1632. https://doi.org/10.1016/j.joen.2010.07.004

[9] Agrawal, M. and Agrawal, V. (2014) Platelet Rich Fibrin and Its Applications in Dentistry: A Review Article. National Journal of Medical and Dental Research, 3, 58.

[10] Khammanit, R., Chantakru, S., Kitiyanant, Y. and Saikhun, J. (2008) Effect of Serum Starvation and Chemical Inhibitors on Cell Cycle Synchronization of Canine Dermal Fibroblasts. Theriogenology, 70, 27-34.

https://doi.org/10.1016/j.theriogenology.2008.02.015

[11] Wang, L.Y., Li, L., Cheng, G. and Zhou, H.M. (2011) Cell Cycle Regulation of Human Foreskin Fibroblasts. African Journal of Biotechnology, 10, 11797-11801.

[12] Liu, C.T., Yu, K.C. and Ju, J.C. (2004) Cell Cycle Stage Analysis of Rabbit Foetal Fibroblasts and Cumulus Cells. Reproduction in Domestic Animals, 39, 385-390. https://doi.org/10.1111/j.1439-0531.2004.00525.x

[13] Weibrich, G., Kleis, W.K.G., Hafner, G. and Hitzler, W.E. (2002) Growth Factor Levels in Platelet-Rich Plasma and Correlations with Donor Age, Sex, and Platelet Count. Journal of Cranio-Maxillo-Facial Surgery, 30, 97-102. https://doi.org/10.1054/jcms.2002.0285

[14] Ghanaati, S., et al. (2014) Advanced Platelet-Rich Fibrin: A New Concept for Cell-Based Tissue Engineering by Means of Inflammatory Cells. Journal of Oral Implantology, 40, 679-689. https://doi.org/10.1563/aaid-joi-D-14-00138

[15] Anitua, E., Andia, I., Ardanza, B., Nurden, P. and Nurden, A.T. (2004) Autologous Platelets as a Source of Proteins for Healing and Tissue Regeneration. Thrombosis and Haemostasis, 91, 4-15.

[16] Vahabi, S., Vaziri, S., Torshabi, M. and Rezaei Esfahrood, Z. (2015) Effects of Plasma Rich in Growth Factors and Platelet-Rich Fibrin on Proliferation and Viability of Human Gingival Fibroblasts. Journal of Dentistry of Tehran University of Medical Sciences, 12, 504-512.

[17] Tsai, C.-H., Shen, S.-Y., Zhao, J.-H. and Chang, Y.-C. (2009) Platelet-Rich Fibrin Modulates Cell Proliferation of Human Periodontally Related Cells in Vitro. Journal of Dental Sciences, 4, 130-135. https://doi.org/10.1016/S1991-7902(09)60018-0

[18] Liu, Y., Kalén, A., Risto, O. and Wahlström, O. (2002) Fibroblast Proliferation Due to Exposure to a Platelet Concentrate in Vitro Is pH Dependent. Wound Repair and Regeneration, 10, 336-340. https://doi.org/10.1046/j.1524-475X.2002.10510.x 